\title{
Field-Based Research in Rural Kenya: Practical Matters and Hurdles
}

Many students arrive in their host country with minimal exposure to and experience with the depth and breadth of conducting a field-based research project. Though SIT students must submit a brief research proposal as part of the admission process, students tend to have only a vague notion of the topic, objectives, methods, location and feasibility of their project proposal. This is only to be expected because for many this is their first time living and studying in a new cultural environment. The students' contextual knowledge, understanding and awareness are limited. Implicit in a field-based research project is that the work is not carried out in a vacuum. In Heather Craig's situation, the culture, its norms and its people, the language, and the infrastructure were very different in nature than what she was used to. Before Heather's proposal was approved by SIT's in-country Academic Director, she needed to demonstrate how she would undertake the practical aspects of being a researcher. What follows is a description of some of the numerous practical factors, which aren't always obvious in the final report, a student like Heather must address before and during the field-based research.

Early in the semester, Heather decided to conduct a study that "...had something to do with the fishing industry and women." So far so good. Since she had never been to Lake Victoria, a preliminary visit to the area was appropriate and pertinent to the research design phase. Finding a reliable and safe means of transport from Nairobi to Kisumu -a bumpy journey of only 165 miles which can take up to 10 hours - was the first hurdle. Public transport in Kenya is sometimes of dubious quality. Even the ticket fare is negotiable. Heather had to find a way to bargain and compromise. Her patience and independent decision-making skills were tested and practiced.

Once in Kisumu, Heather needed a convenient, moderately priced and safe hotel to stay in for the planning days and for the one month independent study period. Next, identifying local organizations that worked on issues relating to the topic was crucial in order to obtain reliable and helpful information as well as approval for the project. This also included ensuring the ongoing support and assistance of a local, preferably expert, academic advisor. Finding dependable and available primary resources for the interviewing process is not as easy as it may sound. Kenyan women are often overburdened with responsibilities, and though they might agree and want to be interviewed, actually showing up for 
the appointment is a very different matter. Flexibility and empathy are necessary skills Heather needed to exercise.

Though she had been studying Kiswahili, Heather didn't speak the language well enough to conduct all the in-depth interviews in that language. Thus, she was faced with the difficult challenge of employing a person who needed to have the language skills to translate from Kiswahili into English, while maintaining objectivity with interviewees, some of whom could easily be a friend or relative of the translator. Heather had to negotiate how much to pay the translator, a complex task for an undergraduate student who most likely is younger and less experienced than the translator. Cooperation, trust, and understanding complex relationships were all aspects that challenged Heather during the research. Her cross-cultural communication skills, understanding, and awareness were put to use on a daily basis.

Responsibility, organization and time management skills were tested as part of being in the field. Heather was required to check in with the Academic Director twice a week. Would there be mobile phone coverage where she planned to be? How else could she stay in touch with the rest of the world? How could she return to Nairobi in case of an emergency? What were the alternate routes and means of transport?

As part of the study's approval process, a budget must be submitted. Included are figures for room and board for the entire four-week period; an estimation of translator and other labor assistance expenses; transport; interviews and meetings; typing and copying. This required Heather to think through all aspects of the project, academic and logistical. A complete schedule of the field period was the last item to be submitted before Heather's project began. This proposal acts as a road map for both the student and program staff, providing guidelines and benchmarks for achievement, as well as emergency planning, risk assessment and contingency planning.

Heather worked diligently on addressing and solving all the above factors to the best of her abilities. Despite the careful planning, she experienced several se backs from her original plan. This is intrinsic to a field-based research project. Overcoming setbacks is yet another learning opportunity for the student, preparing her to creatively problem solve future academic and work challenges.

Perhaps one of the most challenging obstacles that US students face in Kenya is the lack of access to a personal computer. Today's undergraduate students in North America take for granted ubiquitous internet access, spell-check, and the ability to do cut and paste editing as they go. Working throughout the night to finish a term paper is not uncommon for college students. Heather had 
to overcome this assumption. As most of the students in the program, she didn't bring her own computer (since laptops are obvious targets for thieves). Though Kenya has experienced an explosive spread of internet cafés with computing access, most of them close at or around 9 PM. It is also not guaranteed that work produced in a public internet café can be easily saved - maybe there's no CD burner, the owners might have a restriction on using outside media (such as flash drives) or perhaps there's a virus that corrupts files. Further, it is not unusual, in both rural and urban areas, for the electricity supply to be irregular - often cutting out at the least convenient time, for hours or perhaps days, with nobody knowing when it will start again. Working through the realities of computer access poses real challenges to field study.

All of the above aspects are tough and trying challenges for an undergraduate student who is conducting perhaps her first field-based research project. However, in my experience, facing the challenges, paying attention to the rigorous planning requirements, and being ready to deal with the unexpected prepares students for future challenges, possibly including graduate-level research.

Heather Craig succeeded in her academic and personal efforts despite all the expected and unexpected hurdles. The final research report, oral presentation and publication prove that.

Charlotte Blessing

former Academic Director, SIT - Kenya 